\section{OPEN ACCESS}

Edited and reviewed by: Alfredo Pulvirenti, University of Catania, Italy

*Correspondence: Guiying Yan yangy@amss.ac.cn

Specialty section: This article was submitted to Bioinformatics and Computational Biology, a section of the journal

Frontiers in Genetics

Received: 18 December 2019 Accepted: 04 February 2020 Published: 26 February 2020

Citation:

Wang $Q$ and Yan G (2020) Corrigendum: IDLDA: An Improved Diffusion Model for Predicting LncRNA-Disease Associations. Front. Genet. 11:137. doi: 10.3389/fgene.2020.00137

\title{
Corrigendum: IDLDA: An Improved Diffusion Model for Predicting LncRNA-Disease Associations
}

Qi Wang ${ }^{1,2}$ and Guiying Yan ${ }^{1,2 *}$

${ }^{1}$ Academy of Mathematics and Systems Science, Chinese Academy of Sciences, Beijing, China, ${ }^{2}$ School of Mathematical Sciences, University of Chinese Academy of Sciences, Beijing, China

Keywords: long non-coding RNA, disease, association prediction, computational prediction model, diffusion model

\section{A Corrigendum On}

IDLDA: An Improved Diffusion Model for Predicting LncRNA-Disease Associations by Wang $Q$ and Yan G (2019). Front. Genet. 10:1259. doi: 10.3389/fgene.2019.01259

In the original article, there was a mistake in the legend for Figure 2 published as an explanation of what $N_{d}$ and $N_{l}$ represent was missing. The correct legend appears below.

Also in Figure 2 the diagrams shown in Step 2 are incorrect as the formulas were omitted. The corrected Figure 2 and its legend appear below. The authors apologize for this error and state that this does not change the scientific conclusions of the article in any way. The original article has been updated.

Copyright (๑) 2020 Wang and Yan. This is an open-access article distributed under the terms of the Creative Commons Attribution License (CC BY). The use, distribution or reproduction in other forums is permitted, provided the original author(s) and the copyright owner(s) are credited and that the original publication in this journal is cited, in accordance with accepted academic practice. No use, distribution or reproduction is permitted which does not comply with these terms. 
Step1: computing similarities

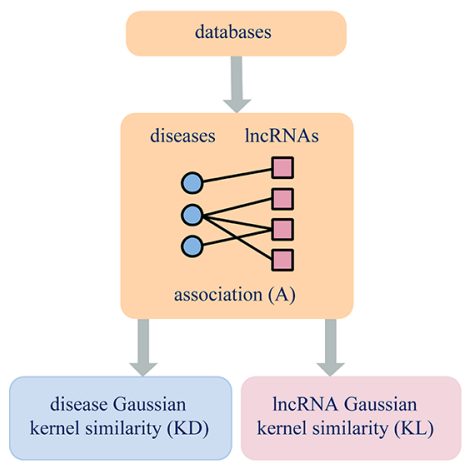

Step2: computing ensemble associations
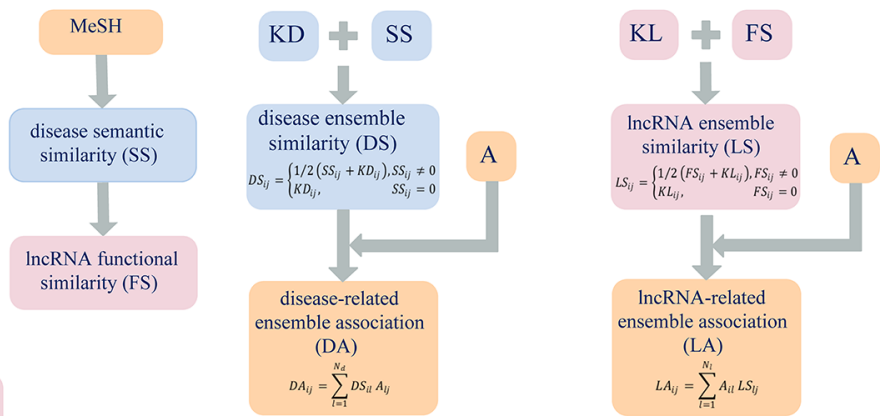

\section{Step3: diffusion on the IncRNA-disease association network}
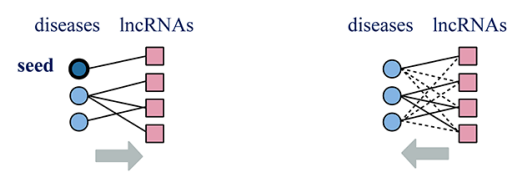

diseases IncRNAs
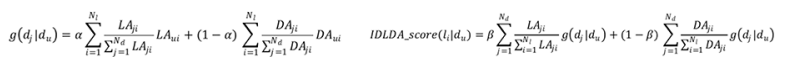

FIGURE 2 | Flowchart of IDLDA. $N_{d}$ and $N_{1}$ represent the number of diseases and the number of IncRNAs, respectively. 